\title{
Accuracy of digital dental models and three-dimensional \\ printed dental models in linear measurements and Bolton
}

\section{analysis [version 1; peer review: 2 approved, 1 approved with}

\author{
reservations]
}

\author{
William Suryajaya (D), Maria Purbiati, Nada Ismah \\ Department of Orthodontics, Faculty of Dentistry, University of Indonesia, Jakarta, Indonesia
}

V1 First published: 04 Mar 2021, 10:180
https://doi.org/10.12688/f1000research.31865.1
Latest published: 01 Sep 2021, 10:180
https://doi.org/10.12688/f1000research.31865.2

\section{Abstract}

Background: Due to advances in digital technology, it is possible to obtain digital dental models through intraoral scanning. The stereolithographic data collected from the scanner can subsequently be printed into a three-dimensional dental model in resinic material. However, the accuracy between digital dental models and printed dental models needs to be evaluated since it might affect diagnosis and treatment planning in orthodontic treatment.

This study aimed to evaluate the accuracy of digital models scanned by a Trios intraoral scanner and three-dimensional dental models printed using a Formlabs 2 3D printer in linear measurements and Bolton analysis.

Methods: A total of 35 subjects were included in this study. All subjects were scanned using a Trios intraoral scanner to obtain digital study models. Stereolithographic data from previous scanning was printed using a Formlabs 2 3D printer to obtain printed study models. Mesiodistal, intercanine, intermolar, and Bolton analysis from all types of study models were measured. The intraclass correlation coefficient was used to assess intraobserver and interobserver reliability. All data were then statistically analyzed.

Results: The reliability tests were high for both intraobserver and interobserver reliability, which demonstrates high reproducibility for all measurements on all model types. Most of the data compared between study models showed no statistically significant differences, though some data differed significantly. However, the differences are considered clinically insignificant.

Conclusion: Digital dental models and three-dimensional printed dental models may be used interchangeably with plaster dental models for diagnostic and treatment planning purposes.

Keywords: Accuracy, 3D printing, digital dental model, printed dental model.

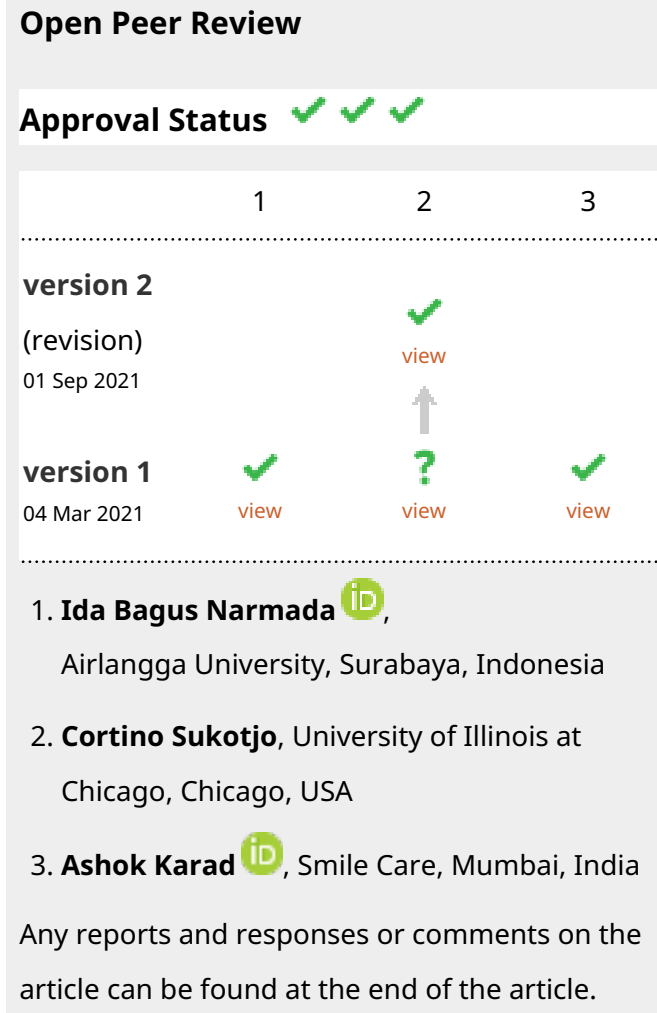

1

2 3

version 2

(revision)

01 Sep 2021

version 1

04 Mar 2021

1. Ida Bagus Narmada (iD),

Airlangga University, Surabaya, Indonesia

2. Cortino Sukotjo, University of Illinois at

Chicago, Chicago, USA

3. Ashok Karad ID, Smile Care, Mumbai, India

Any reports and responses or comments on the article can be found at the end of the article. 


\section{Keywords}

Accuracy, 3D printing, digital dental model, printed dental model

\section{Corresponding authors: William Suryajaya (william_suryajaya@hotmail.com), Nada Ismah (nadalukman@yahoo.com)}

Author roles: Suryajaya W: Conceptualization, Data Curation, Formal Analysis, Funding Acquisition, Investigation, Methodology, Project Administration, Resources, Validation, Visualization, Writing - Original Draft Preparation, Writing - Review \& Editing; Purbiati M:

Conceptualization, Data Curation, Formal Analysis, Funding Acquisition, Investigation, Methodology, Project Administration, Resources, Supervision, Validation, Visualization, Writing - Original Draft Preparation, Writing - Review \& Editing; Ismah N: Conceptualization, Data Curation, Formal Analysis, Funding Acquisition, Investigation, Methodology, Project Administration, Resources, Supervision, Validation, Visualization, Writing - Original Draft Preparation, Writing - Review \& Editing

Competing interests: No competing interests were disclosed.

Grant information: The publication of this manuscript is supported by University of Indonesia. The research was funded by HIBAH PITTA UI research grant.

The funders had no role in study design, data collection and analysis, decision to publish, or preparation of the manuscript.

Copyright: ( $\odot 2021$ Suryajaya W et al. This is an open access article distributed under the terms of the Creative Commons Attribution License, which permits unrestricted use, distribution, and reproduction in any medium, provided the original work is properly cited.

How to cite this article: Suryajaya W, Purbiati M and Ismah N. Accuracy of digital dental models and three-dimensional printed dental models in linear measurements and Bolton analysis [version 1; peer review: 2 approved, 1 approved with reservations] F1000Research 2021, 10:180 https://doi.org/10.12688/f1000research.31865.1

First published: 04 Mar 2021, 10:180 https://doi.org/10.12688/f1000research.31865.1 


\section{Introduction}

Dental models are essential in the process of determining diagnosis and treatment planning in orthodontic treatment ${ }^{1-3}$. Commonly used dental models are made of plaster, which can easily be fractured and lost ${ }^{4}$. Aside from that, plaster models require storage room, which can be problematic since typical dental practices have limited space, and the number of models will continue to grow as the number of patients treated grows 5 . Moreover, the process of obtaining plaster models requires taking impressions with impression material, which can be an unpleasant experience for patients ${ }^{6}$.

Recent developments in digital technology have made digitalization of dental models possible. Using an intraoral scanner, a patient's oral condition, especially the teeth, can be registered and stored in a computer ${ }^{7}$. The scanned data is in the form of stereolithographic data that can be retrieved from the computer storage system almost instantly. The advantage of digital study models is that they are not prone to damage, fracture, or loss. Not only is no extra space needed to store the models, digital models also make setting up models and sending models for referral easy ${ }^{8-10}$.

Generally, intraoral scanners record intraoral structures with a camera located on the tip of a wand that emits light. The light is then reflected back by the surface of the intraoral structures and recaptured by the camera to create digital objects ${ }^{11}$. There are several intraoral scanners available on the market, such as iTero (Align Technologies, San Jose, CA), Lava Chairside Oral Scanner (COS) (3M ESPE, Seefeld, Germany), and Trios (3Shape, Copenhagen, Denmark). Of these scanners, Lava COS requires the addition of titanium oxide to opacify the tooth surface so that the light from the camera on the wand can be optimally reflected. This addition may affect the accuracy of the recorded digital model since it adds thickness to the teeth $^{12}$.

Stereolithographic data obtained from previous scanning can be printed using a $3 \mathrm{D}$ printer to produce a printed model ${ }^{8,9}$. When necessary, the printed model is especially beneficial in diagnosing complex cases when a tangible model would make the diagnosis easier. There are several 3D printer technologies available, such as Fusion Deposition Modelling, an inkjet-based system or 3DP, and stereolithography (SLA). Each 3D printer has its own method of producing 3D objects ${ }^{13}$. However, the accuracy of a printed model may be altered since two steps are required to produce the printed model: scanning from the intraoral structure and printing it into resinic material.

The accuracy of dental models in recording intraoral structures is paramount since inaccuracy may lead to inaccurate diagnosis and treatment planning ${ }^{14}$. Hence, it is important to evaluate the accuracy of various dental models compared to the commonly accepted instrument: plaster models. Several studies have confirmed that digital models are suitable to replace plaster models ${ }^{11,14,15}$. However, limited studies are available that assess the accuracy of printed models, which have to go through the two steps of scanning and printing. This study aims to evaluate the linear accuracy and Bolton analysis ${ }^{16}$ of digital dental models scanned using Trios and resinic dental models printed using Formlabs 2 and compare them to plaster dental models.

\section{Methods}

Subjects

This prospective observational analytical study was approved by the Ethical Committee of the University of Indonesia (approval number of 49/Ethical Approval/FKG UI/VI/2019). The subjects were graduate and undergraduate dental students at the University of Indonesia who agreed to participate in the study and signed informed consents after being briefed about the details of the study. Sample size was calculated using Gpower Software version 3.1 for windows with the premises: normal data distribution, $\alpha=0.05, \beta=80 \%$, and effect size $=0.5$ and the result signified a minimum sample of 34 . Based on convenience sampling, a total of 35 subjects (mean age: $24.85 \pm 3.9$ years old), five males and 30 females, were selected based on the following inclusion criteria: (1) 16-50 years old, (2) total crowding on each jaw not exceeding $3 \mathrm{~mm}$, and (3) all teeth from central incisors to first molars on each quadrant are present. The exclusion criteria were: (1) large filling or restoration on the proximal side of the measured teeth and (2) incomplete impression or scanning results. This study was conducted at Graduate Orthodontic Clinic at the University of Indonesia Teaching Dental Hospital between June 2019 until August 2019.

\section{Digital model}

All subjects were scanned using Trios (3Shape, Copenhagen, Denmark) on both the maxilla and mandible. All teeth from the central incisors to the first molars were thoroughly scanned so as to produce complete sets of teeth on the digital model. Stereolithographic data from the scanning procedure were saved on a computer hard drive.

\section{Printed model}

All stereolithographic data were subsequently printed using a Formlabs 2 SLA 3D printer (Formlabs, Somerville, MA) to produce printed dental models of both the upper and lower jaws of all subjects.

\section{Plaster model}

After the scanning procedure was complete, impressions were taken from all subjects with alginate impression material (Hydrogum, Zhermack Dental, Badia Polesine, Italy). The impression was consequently poured with type II dental stone (Pro Model Super 11, Saint Gobain, France) to obtain a plaster dental model.

\section{Data collection}

The mesiodistal widths of all teeth from the central incisors to the first molars on each quadrant of all models were measured. Subsequently, the intercanine and intermolar widths were also measured. All measurements on the plaster and printed models were measured using a digital caliper (Mitutoyo, Japan), while the digital models were measured using builtin measurement tools on Autodesk Netfabb Premium 2019 (RRID:SCR_019812) software as described in previous study 
by Akyalcin et al. ${ }^{17}$ Approximately $10 \%$ of each model was measured by another observer (MP) to assess interobserver reliability. Interobserver reliability was assessed using the intraclass coefficient (ICC) and showed almost perfect agreement (ICC > 0.9). Within two weeks after the first measurements, $10 \%$ of all models were measured again by the same observer (WS) to assess intraobserver reliability. Intraobserver reliability was assessed using the ICC and reached almost perfect agreement (ICC > 0.9) between the first and second observations. Bolton analysis was then measured using the collected mesiodistal width data.

\section{Statistical analysis}

All data were analyzed using the Statistical Package for the Social Sciences (SPSS) version 20.0 for Windows (RRID: SCR_019096). The data normality of each group was assessed using the Shapiro-Wilk test. Repeated measures ANOVA was used for parametric numeric data, while the Friedman test was used to compare nonparametric numeric data. Within-group differences were assessed using the paired t-test for parametric data sets, while the Wilcoxon test was used for nonparametric data sets. A p-value $<0.05$ was considered statistically significant.

\section{Results}

The flow of participants is shown in Figure 1.

Reliability test

The reliability of all criteria in this study was tested using the ICC. All data tested, including mesiodistal, intercanine, and intermolar width for both interobserver and intraobserver, were found to be reliable with high agreement (Table 1 and Table 2).

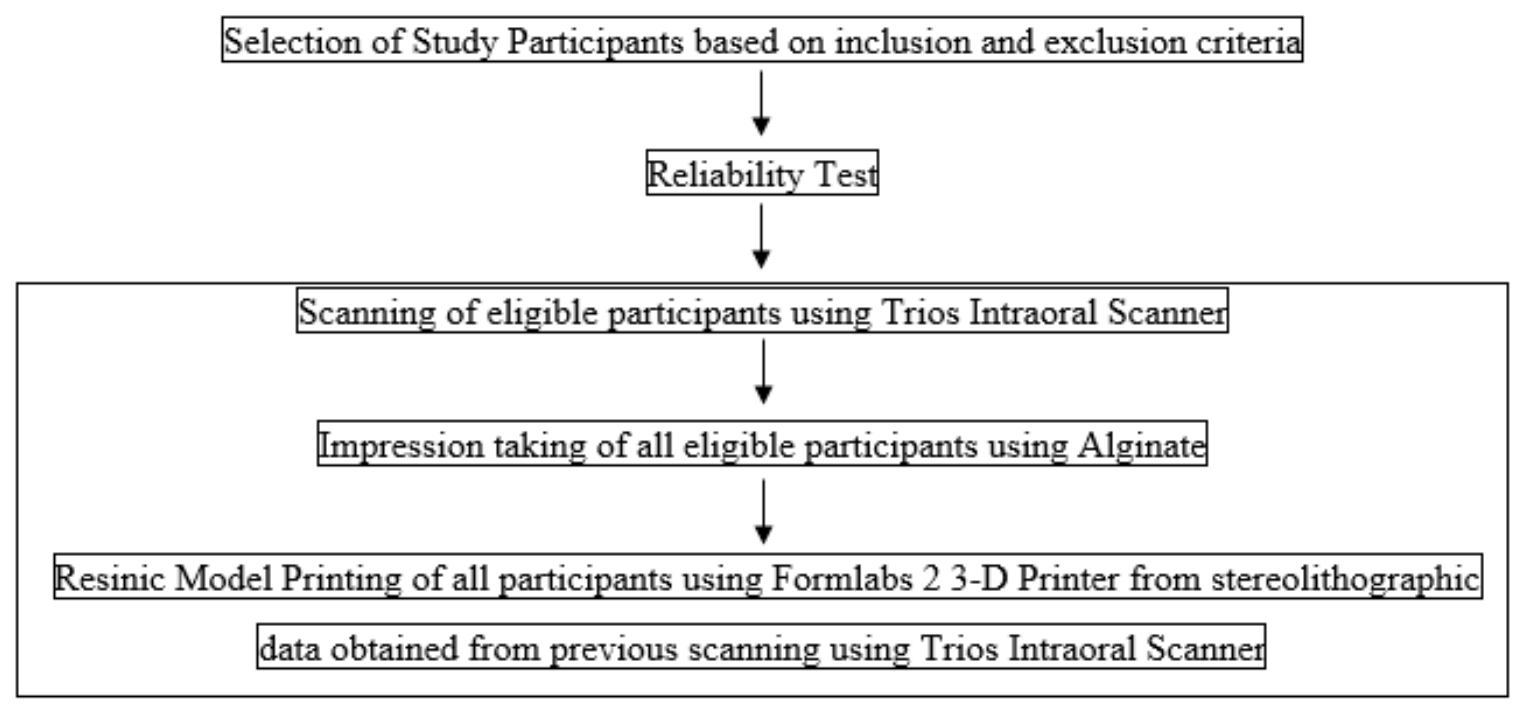

Figure 1. Flow of participants.

\begin{tabular}{l}
\hline Table 1. Intraobserver reliability. \\
\hline Component
\end{tabular}

\begin{tabular}{|c|c|c|c|}
\hline \multirow[t]{2}{*}{ Component } & \multicolumn{3}{|c|}{ Agreement Interoberserver* } \\
\hline & $\begin{array}{r}\text { Plaster } \\
\text { Model }\end{array}$ & $\begin{array}{l}\text { Digital } \\
\text { Model }\end{array}$ & $\begin{array}{l}\text { Resin } \\
\text { Model }\end{array}$ \\
\hline Mesiodistal & 0.991 & 0.958 & 0.990 \\
\hline Intercanine & 0.994 & 0.997 & 0.993 \\
\hline Intermolar & 0.988 & 0.997 & 0.993 \\
\hline \multicolumn{4}{|c|}{$\begin{array}{l}\text { *: ICC: }<0.20 \text { : poor agreement | } 0.21-0.40 \text { : fair } \\
\text { agreement | 0.41-0.60: moderate agreement | } \\
0.61-0.80 \text { : substantial agreement | } 0.81-1.00: \text { almost } \\
\text { perfect agreement }\end{array}$} \\
\hline
\end{tabular}


Mesiodistal width

A total of eight different teeth $(11,13,14,16,31,33,34,36)$ were chosen to represent each of the tooth types on each jaw. Almost all data were normally distributed except 11 and 31. This is probably due to the various tooth sizes between individual subjects. All group comparisons (Table 3) showed statistically significant differences $(\mathrm{p}<0.05)$ on 13 and 16 . Further within-group analysis (Table 4) revealed statistically significant differences $(\mathrm{p}<0.05)$ between printed models and plaster models on both teeth.
Intercanine and intermolar width

The intercanine and intermolar widths of all groups were compared, and significant differences $(\mathrm{p}<0.05)$ were found for mandibular intercanine, maxillary intermolar, and mandibular intermolar (Table 5 and Table 6). Further comparison analysis between groups revealed a significant difference for maxillary intercanine between the digital model-printed model and printed model-plaster model (Table 7). Significant differences $(\mathrm{p}<0.05)$ between groups were found for the digital model-printed model and the printed model-plaster model for the maxillary

Table 3. Mean Comparison of Mesiodistal Width.

\begin{tabular}{|r|r|r|r|r|r|r|r|}
\hline $\begin{array}{c}\text { Tooth } \\
\text { Number }\end{array}$ & \multicolumn{5}{|c|}{ Mesiodistal Width } & p-Value \\
\cline { 2 - 8 } & Plaster Model & \multicolumn{1}{|c|}{ Digital Model } & Printed Model & \\
\hline & Mean & SD & Mean & SD & Mean & SD & \\
\hline 11 & 8.32 & 0.42 & 8.3 & 0.45 & 8.32 & 0.50 & 0.871 \\
\hline 13 & 7.78 & 0.59 & 7.88 & 0.52 & 7.94 & 0.57 & 0.007 * \\
\hline 14 & 7.33 & 0.56 & 7.42 & 0.52 & 7.41 & 0.49 & 0.097 \\
\hline 16 & 10.2 & 0.54 & 10.23 & 0.52 & 10.35 & 0.50 & 0.017 \\
\hline 31 & 5.2 & 0.29 & 5.26 & 0.40 & 5.2 & 0.33 & 0.765 \\
\hline 33 & 6.76 & 0.50 & 6.73 & 0.50 & 6.8 & 0.48 & 0.454 \\
\hline 34 & 7.36 & 0.50 & 7.35 & 0.50 & 7.43 & 0.56 & 0.298 \\
\hline 36 & 11.02 & 0.58 & 11.02 & 0.57 & 11.13 & 0.57 & 0.073 \\
\hline
\end{tabular}

Table 4. Between-Group Comparison of Mesiodistal Width.

\begin{tabular}{|l|r|r|r|}
\hline $\begin{array}{l}\text { Tooth } \\
\text { Number }\end{array}$ & \multicolumn{3}{|c|}{ Between Group Comparison (p-value) } \\
\hline & $\begin{array}{r}\text { Plaster Model } \\
\text { - Digital Model }\end{array}$ & $\begin{array}{r}\text { Digital Model } \\
\text { - Printed Model }\end{array}$ & $\begin{array}{r}\text { Printed Model } \\
\text { - Plaster Model }\end{array}$ \\
\hline 13 & 0.155 & 0.843 & $0.000^{\star}$ \\
\hline 16 & 1.000 & 0.119 & $0.016^{\star}$ \\
\hline
\end{tabular}

Table 5. Mean Comparison of Intercanine Width.

\begin{tabular}{|l|r|r|r|r|r|r|r|r|}
\hline \multirow{2}{*}{ Jaw } & \multicolumn{9}{|c|}{ Intercanine Width } & p-value \\
\hline & Plaster Model & \multicolumn{2}{|c|}{ Digital Model } & Printed Model & \\
\hline & Mean & SD & Mean & SD & Mean & SD & \\
\hline Maxilla & 34.67 & 1.98 & 34.88 & 1.89 & 34.82 & 2.88 & 0.520 \\
\hline Mandible & 26.56 & 1.89 & 26.87 & 2.06 & 26.03 & 1.89 & $0.000^{*}$ \\
\hline
\end{tabular}


intermolar teeth and for the printed model-plaster model and plaster model-digital model for mandibular intermolar teeth.

\section{Bolton analysis}

The data collected for the Bolton analysis were compared. A significant difference $(\mathrm{p}<0.05)$ was found on anterior Bolton analysis (Table 8). A positive result showed tooth excess on maxillary teeth, and a negative result showed tooth excess on mandibular teeth. Comparisons between groups showed significant differences for the printed model-plaster model and the plaster model-digital model on anterior Bolton analysis (Table 9).

Table 6. Mean Comparison of Intermolar Width.

\begin{tabular}{|l|r|r|r|r|r|r|r|}
\hline & \multicolumn{7}{|c|}{ Intermolar } \\
\hline \multirow{2}{*}{ Jaw } & Plaster Model & \multicolumn{2}{|c|}{ Digital Model } & Printed Model & p-value \\
& Mean & SD & Mean & SD & Mean & SD & \\
\hline Maxilla & 47.08 & 2.19 & 47.49 & 2.39 & 48.13 & 2.16 & $0.000^{*}$ \\
\hline Mandible & 40.93 & 2.27 & 41.22 & 2.39 & 41.40 & 2.29 & $0.000 *$ \\
\hline
\end{tabular}

Table 7. Between-Group Comparison Between Intermolar and Intercanine Width.

\begin{tabular}{|l|r|r|r|}
\hline \multicolumn{1}{|c|}{ Component } & \multicolumn{3}{|c|}{ Between-Group Comparisons (p-value) } \\
\hline & $\begin{array}{r}\text { Plaster Model } \\
\text { - Digital Model }\end{array}$ & $\begin{array}{r}\text { Digital Model } \\
\text { - Printed Model }\end{array}$ & $\begin{array}{r}\text { Printed Model } \\
\text { - Plaster Model }\end{array}$ \\
\hline Maxillary Intercanine & 0.441 & $0.035^{\star}$ & 0.204 \\
\hline Mandibular Intercanine & 0.478 & $0.000^{*}$ & $0.000^{\star}$ \\
\hline Maxillary Intermolar & 0.073 & $0.001 *$ & $0.000^{\star}$ \\
\hline Mandibular Intermolar & $0.003^{*}$ & 0.320 & $0.001^{\star}$ \\
\hline
\end{tabular}

Table 8. Mean Comparison Using Bolton Analysis.

\begin{tabular}{|l|r|r|r|r|r|r|r|r|}
\hline \multirow{2}{*}{ Component } & \multicolumn{4}{|c}{ Tooth Material Excess } & \multicolumn{3}{|c|}{ p-value } \\
\cline { 2 - 8 } & Plaster Model & \multicolumn{1}{|c|}{ Digital Model } & Printed Model & \\
\hline & Mean & SD & Mean & SD & Mean & SD & \\
\hline Anterior & 0.37 & 1.25 & $-0.18^{* *}$ & 0.97 & 0.56 & 1.81 & $0.041 *$ \\
\hline Overall & 0.60 & 2.07 & 0.18 & 1.98 & 0.55 & 2.64 & 0.391 \\
\hline
\end{tabular}

**: excess on mandibular teeth

Table 9. Between Group Comparison Using Bolton Analysis.

\begin{tabular}{|l|r|r|r|}
\hline Component & \multicolumn{3}{|c|}{ Between Groups Comparison (p-value) } \\
\hline & $\begin{array}{r}\text { Plaster Model } \\
\text { - Digital Model }\end{array}$ & $\begin{array}{r}\text { Digital Model } \\
\text {-Printed Model }\end{array}$ & $\begin{array}{r}\text { Printed Model } \\
\text { - Plaster Model }\end{array}$ \\
\hline Bolton Anterior & $0.006 *$ & $0.020 *$ & 0.935 \\
\hline Bolton Overall & 0.366 & 1.000 & 1.000 \\
\hline
\end{tabular}




\section{Discussion}

Mesiodistal width, intercanine width, intermolar width, and Bolton analysis were compared between the plaster models, digital models, and printed models. Measurements on the digital models were found to be challenging, as a digital model is a three-dimensional object to be seen on the two-dimensional spectrum of a computer screen. All measurements were conducted by one observer, which makes the measurements more reliable ${ }^{8}$.

While the comparison of the mesiodistal widths of the measured teeth showed varied results, most of the teeth measured had no statistically significant difference. If the difference was found to be significant, it was within the range of $0.15 \mathrm{~mm}$, which was deemed clinically insignificant. It must be noted that between-group comparison revealed the difference was between the plaster models and printed models. The same result was found by Brown et al. ${ }^{18}$ The difference is probably due to instability of alginate impressions. Alginate is unstable at room temperature, so it can absorb water from the air through the process of imbibition, which causes alginate to enlarge ${ }^{19}$. Moreover, 3D printer minimum thickness may play a role in the difference. The minimum thickness can cause the printed model to be bigger than usual even though the minimum thickness is relatively small $(25 \mu \mathrm{m})$. The differences for mesiodistal width between the plaster models and digital models were found to be insignificant.

Intercanine and intermolar comparison in this study showed statistically significant differences for mandibular intercanine, maxillary intermolar, and mandibular intermolar. However, even though the differences were statistically significant, they were rendered clinically insignificant since the mean difference was not more than $1.5 \mathrm{~mm}$. De Waard et al. ${ }^{20}$ found a similar result, although the digital models in their study were obtained from cone-beam computed tomography scanning of plaster models. Another study by Brown et al. ${ }^{18}$ found that there were no statistically significant differences between printed models and plaster models. However, the 3D printer used in that study was a polyjet and DLP printer, which has a minimum thickness ranging from $15 \mu \mathrm{m}$ to $50 \mu \mathrm{m}$, while the printer used in the present study was an SLA printer, which has a minimum thickness of $50 \mu \mathrm{m}$.

Bolton analysis measurement showed a statistically significant difference for anterior Bolton analysis. Even though the difference was significant, the Bolton analysis measurement difference was not more than $1.5 \mathrm{~mm}$, which is clinically insignificant ${ }^{21}$. Several studies have revealed the same result as this study for Bolton analysis comparison between different dental models ${ }^{8,11}$. Bolton analysis is a very sensitive technique.
Measurement by the same observer on the same model may produce a different result ${ }^{22}$. Hence, the statistically significant difference in this study was rendered clinically insignificant.

Several limitations and difficulties were present on this study. Plaster model as gold standard reference measurement does not represent the actual size of each tooth since both the impression material and the plaster used in the making of plaster model may shrink and cause disparity from actual tooth size. Measurement on dry skull as reference might be more appropriate on similar future study since measurement on patient is both difficult and inconvenience. Moreover, selection of 3D printer model might enhance the accuracy of the study. $3 \mathrm{D}$ printer that can print $3 \mathrm{D}$ object with less minimum thickness than that of used in this study is preferable to produce more accurate resin model.

\section{Conclusion}

Digital models and printed models may be considered to replace plaster models to diagnose and plan treatment for orthodontic cases because the linear measurement and Bolton analysis between the different study models mostly showed no statistically significant differences. Even when the difference was statistically significant, it was negligible clinically.

\section{Consent}

All participants provided written informed consent before involvement in the study.

\section{Data availability}

Underlying data

Figshare: Research Data, https://doi.org/10.6084/ m9.figshare.13469160.v1 $1^{23}$

This project contains the following underlying data:

- $\quad$ Linear measurements

- Bolton Analysis of dental stone, digital, and printed models

Figshare: Stereolihographic Data, https://doi.org/10.6084/ m9.figshare.13469172.v124

This project contains the following underlying data:

- Stereolithographic data obtained from scanning subjects' dentition.

Data are available under the terms of the Creative Commons Zero "No rights reserved" data waiver (CCO 1.0 Public domain dedication). 
1. Coubourne MT, DiBiase AT: Handbook of Orthodontics. 2nd Edition. Edinburgh: Mosby; 2016; 143

Reference Source

2. Han UK, Vig KWL, Weintraub JA, et al.: Consistency of orthodontic treatment decisions relative to diagnostic records. Am J Orthod Dentofac Orthop. 1991; 100(3): 212-219.

PubMed Abstract | Publisher Full Text

3. Sofyanti E, Boel T, Satria D, et al.: Differences in dental arch characteristics between genders in patients with suspected condylar hyperplasia in a North Sumatra subpopulation: a cross-sectional study [version 3 ; peer review : 3 approved]. F1000Res. 2020; 9: 263.

PubMed Abstract | Publisher Full Text | Free Full Text

4. Jacob HB, Wyatt GD, Buschang PH: Reliability and validity of intraoral and extraoral scanners. Prog Orthod. 2015; 16: 38. PubMed Abstract | Publisher Full Text | Free Full Text

5. El-zanaty HM, El-beialy AR, El-ezz AMA, et al.: Three-dimensional dental measurements: An alternative to plaster models. Am J Orthod Dentofac Orthop. 2010; 137(2): 259-265.

PubMed Abstract | Publisher Full Text

6. Burhardt L, Livas C, Kerdijk W, et al.: Treatment comfort, time perception, and preference for conventional and digital impression techniques: A comparative study in young patients. Am J Orthod Dentofac Orthop. 2016: 150(2): 261-267.

PubMed Abstract | Publisher Full Text

7. Peluso MJ, Josell SD, Levine SW, et al.: Digital Models: An Introduction. Semin Orthod. 2004; 10(3): 226-238.

Publisher Full Text

8. Wiranto MG, Engelbrecht WP, Tutein Nolthenius HE, et al.: Validity, reliability, and reproducibility of linear measurements on digital models obtained from intraoral and cone-beam computed tomography scans of alginate impressions. Am J Orthod Dentofac Orthop. 2013; 143(1): 140-147. PubMed Abstract | Publisher Full Text

9. Grünheid T, McCarthy SD, Larson BE: Clinical use of a direct chairside oral scanner: An assessment of accuracy, time, and patient acceptance. $\mathrm{Am}$ Orthod Dentofac Orthop. 2014; 146(5): 673-682.

PubMed Abstract | Publisher Full Text

10. Ko H, Liu W, Hou D, et al.: Agreement of treatment recommendations based on digital vs plaster dental models. Am J Orthod Dentofac Orthop. 2019; 155(1): 135-142.

PubMed Abstract | Publisher Full Text

11. Atia MA, El-Gheriani AA, Ferguson DJ: Validity of $\mathbf{3}$ Shape Scanner Techniques: A Comparison with the Actual Plaster Study casts. Biometrics Biostat Int J. 2015; 2(2): 64-69.

Publisher Full Text

12. Meyer BJ, Mörmann WH, Lutz F: Optimization of the powder application in the Cerec method with environment-friendly propellant systems. Schweiz Monatsschr Zahnmed. 1990; 100(12): 1462-1468.

PubMed Abstract

13. Torabi K, Farjood E, Hamedani S: Rapid Prototyping Technologies and their Applications in Prosthodontics, a Review of Literature. J Dent (Shiraz). 2015, 16(1): 1-9.

PubMed Abstract | Free Full Text

14. Fleming PS, Marinho V, Johal A: Orthodontic measurements on digital study models compared with plaster models: A systematic review. Orthod Craniofacial Res. 2011; 14(1): 1-16.

PubMed Abstract | Publisher Full Text

15. Rossini G, Parrini S, Castroflorio T, et al.: Diagnostic accuracy and measurement sensitivity of digital models for orthodontic purposes: A systematic review. Am J Orthod Dentofac Orthop. 2016; 149(2): 161-170. PubMed Abstract | Publisher Full Text

16. Bolton WA: Disharmony in tooth size and its relation to the analysis and treatment of malocclusion. Angle Orthod. 1958; 28(3): 113-130.

Publisher Full Text

17. Akyalcin S, Cozad BE, English JD, et al.: Diagnostic accuracy of impression-free digital models. Am J Orthod Dentofac Orthop. 2013; 144(6): 916-922. PubMed Abstract | Publisher Full Text

18. Brown GB, Currier GF, Kadioglu O, et al:: Accuracy of 3-dimensional printed dental models reconstructed from digital intraoral impressions. $A m$ J Orthod Dentofac Orthop. 2018; 154(5): 733-739. PubMed Abstract | Publisher Full Text

19. Todd JA, Oesterle LJ, Newman SM, et al.: Dimensional changes of extendedpour alginate impression materials. Am J Orthod Dentofac Orthop. 143(4 Suppl): S55-S63. PubMed Abstract | Publisher Full Text

20. de Waard O, Rangel FA, Fudalej PS, et al:: Reproducibility and accuracy of linear measurements on dental models derived from cone-beam computed tomography compared with digital dental casts. Am J Orthod Dentofac Orthop. 2014; 146(3): 328-336. PubMed Abstract | Publisher Full Text

21. Proffit W: Contemporary Orthodontics. 5th Edition. St. Louis: Mosby; 2012. Reference Source

22. Tomassetti JJ, Taloumis LJ, Denny JM, et al.: A Comparison of $\mathbf{3}$ Computerized Bolton Tooth-Size Analyses with a Commonly Used Method. Angle Orthod. 2001; 71(5): 351-357.

PubMed Abstract | Publisher Full Text

23. Suryajaya W: Research Data. figshare. Dataset. 2021. http://www.doi.org/10.6084/m9.figshare.13469160.v1

24. Suryajaya W: Stereolithographic Data. figshare. Figure. 2021. http://www.doi.org/10.6084/m9.figshare.13469172.v1 


\section{Open Peer Review}

\section{Current Peer Review Status:}

\section{Version 1}

Reviewer Report 26 April 2021

https://doi.org/10.5256/f1000research.34922.r80963

(C) 2021 Karad A. This is an open access peer review report distributed under the terms of the Creative Commons Attribution License, which permits unrestricted use, distribution, and reproduction in any medium, provided the original work is properly cited.

\section{Ashok Karad}

Smile Care, Mumbai, Maharashtra, India

Dental study models are one of the important diagnostic aids and their accuracy affects the diagnosis and treatment planning. This study has evaluated the linear accuracy and Bolton analysis of digital dental models and printed models and compared them to plaster dental models. The authors have done good work in analysing various parameters and providing a useful and clinically-relevant information. The contents have been clearly and accurately presented in the manuscript. The results of the study have been discussed comprehensively and are supported with appropriate references.

However, the following minor concerns need to be addressed by the authors to provide more clarity and better understanding:

1. The manuscript requires one more round of linguistic/ grammatical editing.

2. In 'Methods' section, it is appropriate to use the term 'Ethics committee' instead of 'Ethical committee'.

3. The figure 1 legend should be 'Flow of events' instead of 'Flow of participants'. Make corresponding changes in the manuscript as well.

Is the work clearly and accurately presented and does it cite the current literature? Yes

Is the study design appropriate and is the work technically sound? Yes

Are sufficient details of methods and analysis provided to allow replication by others? Yes

If applicable, is the statistical analysis and its interpretation appropriate? 


\section{I cannot comment. A qualified statistician is required.}

Are all the source data underlying the results available to ensure full reproducibility? Yes

Are the conclusions drawn adequately supported by the results? Yes

Competing Interests: No competing interests were disclosed.

Reviewer Expertise: Orthodontic clinical work and research

I confirm that I have read this submission and believe that I have an appropriate level of expertise to confirm that it is of an acceptable scientific standard.

Author Response 24 Aug 2021

William Suryajaya, University of Indonesia, Jakarta, Indonesia

Dear Reviewer,

Thank you for your valuable inputs. Here are our response:

1. We have made an attempt to cross this article through a professional grammar editing process.

2. Noted and will be revised.

3. Noted and will be revised.

Thank you

Competing Interests: No competing interests were disclosed.

Reviewer Report 29 March 2021

https://doi.org/10.5256/f1000research.34922.r80964

(c) 2021 Sukotjo C. This is an open access peer review report distributed under the terms of the Creative Commons Attribution License, which permits unrestricted use, distribution, and reproduction in any medium, provided the original work is properly cited.

\section{Cortino Sukotjo}

Department of Restorative Dentistry, University of Illinois at Chicago, Chicago, IL, USA

Dear authors, thank you very much for your article.

1. Please convert table 3-9 to graphs, so that you can include p-value comparisons between 
group.

2. The gold standard is plaster model, however, you mentioned many disadvantages of plaster model, which could confuse the reader who is not orthodontist.

3. You mentioned that some values were significantly different, but were they clinically significant?

4. In your conclusion, you mentioned that: "Digital models and printed models may be considered to replace plaster models to diagnose and plan treatment for orthodontic cases". Actually, in many developed countries, digital models have been used in orthodontic offices daily. Please revise your conclusion.

Is the work clearly and accurately presented and does it cite the current literature? Partly

Is the study design appropriate and is the work technically sound?

Partly

Are sufficient details of methods and analysis provided to allow replication by others? Yes

If applicable, is the statistical analysis and its interpretation appropriate? Yes

Are all the source data underlying the results available to ensure full reproducibility? Yes

Are the conclusions drawn adequately supported by the results?

No

Competing Interests: No competing interests were disclosed.

Reviewer Expertise: Research

I confirm that I have read this submission and believe that I have an appropriate level of expertise to confirm that it is of an acceptable scientific standard, however I have significant reservations, as outlined above.

Author Response 24 Aug 2021

William Suryajaya, University of Indonesia, Jakarta, Indonesia

Dear reviewer,

Thank you for the valuable input and here are our response:

1. Yes, we have replaced the tables with graphs so as to make the reader easier to compare 
between the p-values.

2. Plaster model is still the gold-standard study models in most parts of the worlds, especially in the less developed country. However, since it has many disadvantages, efforts to replace them with a more precise and accurate models has been very rigorous. One of the effort is to replace them with digital models and printed models.

3. As mentioned, a couple of times in the article and citing some references, we mentioned that the differences are clinically insignificant though statistically significant.

4. We have made revision accordingly.

Thank you.

Competing Interests: No competing interests were disclosed.

Reviewer Report 17 March 2021

https://doi.org/10.5256/f1000research.34922.r80961

(c) 2021 Narmada I. This is an open access peer review report distributed under the terms of the Creative Commons Attribution License, which permits unrestricted use, distribution, and reproduction in any medium, provided the original work is properly cited.

\section{Ida Bagus Narmada}

Department of Orthodontics, Faculty of Dental Medicine, Airlangga University, Surabaya, Indonesia

The authors of this study have evaluated the linear accuracy and Bolton analysis of digital dental models scanned using Trios and resinic dental models printed using Formlabs 2 and compare them to plaster dental models. The results are certainly interesting and the authors are commended for executing this study.

However, the authors need to address the following minor concerns:

\section{General:}

The paper is well organized and easy to follow.

Novelty is sufficient and high impact.

To improve the readability, it is recommended that the text is checked by a native English speaking person as many of the sentences might be misunderstood. I suggest a revision of the English grammar structures by an expert editor in revising manuscripts.

\section{Introduction:}

No revision is needed. 
Results:

Please provide and add some information about standard deviation of the data.

Is it possible to combine the tables to reduce the number of the tables? ( 9 tables are too many).

\section{Discussion:}

Discussion of the results is quite comprehensive. In analyzing the results, the authors also show citations from the previous study to support the explanation of these results.

The answer to the hypothesis of this study should be included at the beginning of the discussion section.

Please mention the limitation of this study and the suggestion for future study in the discussion section.

\section{Conclusion:}

The conclusion section is quite comprehensive. However, please add the clinical implication from this study result.

\section{References:}

The supporting references are adequate for the medium article.

Is the work clearly and accurately presented and does it cite the current literature? Yes

Is the study design appropriate and is the work technically sound?

Yes

Are sufficient details of methods and analysis provided to allow replication by others? Yes

If applicable, is the statistical analysis and its interpretation appropriate? Partly

Are all the source data underlying the results available to ensure full reproducibility? Partly

Are the conclusions drawn adequately supported by the results? Yes

Competing Interests: No competing interests were disclosed.

Reviewer Expertise: Orthodontics and Orthopaedic Dentofacial

I confirm that I have read this submission and believe that I have an appropriate level of expertise to confirm that it is of an acceptable scientific standard. 
William Suryajaya, University of Indonesia, Jakarta, Indonesia

Dear Reviewer,

Thank you for the valuable suggestions. Here are our response:

We have made revisions accordingly. Notably, We replaced the tables with graphs so as to limit the number of the tables in the article.

Thank you

Competing Interests: No competing interests were disclosed.

The benefits of publishing with F1000Research:

- Your article is published within days, with no editorial bias

- You can publish traditional articles, null/negative results, case reports, data notes and more

- The peer review process is transparent and collaborative

- Your article is indexed in PubMed after passing peer review

- Dedicated customer support at every stage

For pre-submission enquiries, contact research@f1000.com 